\title{
PEMBUATAN APLIKASI ANDROID DENGAN CEPAT MENGGUNAKAN ISPRING UNTUK MENUNJANG PEMBELAJARAN SECARA DARING
}

\author{
Miftahul Jannah ${ }^{1}{ }^{*}$, Aminatul Husna2 ${ }^{2}$ Siti Nurhalimah ${ }^{3}$
}

Program Studi Ilmu Pengetahuan Alam Institut Agama Islam Negeri Jember

Corresponding Author: jannah170699@gmail.com

\begin{abstract}
Abstrak. Penelitian ini bertujuan untuk mengetahui pembuatan aplikasi android menggunakan iSpring sebagai alternatif desain dalam pembuatan media pembelajaran daring. Metode penelitian ini menggunakan metode Library Research atau Kajian Kepustakaan. Ispring Presenter merupakan salah satu tool yang mengubah file presentasi yang kompatibel dengan Power Point untuk menjadikan bentuk Flash. Pembelajaran e-learning mengguakan iSpring membantu peserta didik dalam memanfaatkan teknologi dengan cerdas. Proses pembelajaran menggunakan iSpring, akan membantu peserta didik belajar sesuai dengan gaya belajar setiap peserta didik serta mendapatkan kebebasan saat belajar tampa keterbatasan waktu dan lokasi. Proses belajar mengajar lebih menarik, sehingga dapat memotivasi dan materi yang disampaikan dalam desain aplikasi ispring lebih dapat dipahami.
\end{abstract}

Kata kunci: Ispring, Media Pembelajaran, Teknologi

\begin{abstract}
This study aims to determine the making of android applications using iSpring as an alternative design in making online learning media. This research method uses the Library Research method or literature review. Ispring Presenter is a tool that converts PowerPoint compatible presentation files to Flash format. E-learning learning using iSpring helps students to use technology smartly. The learning process using iSpring, will help students learn in accordance with the learning style of each student and get freedom when learning without the limitations of time and location. The teaching and learning process is more interesting, so that it can motivate and the material presented in the iSpring application design is more understandable.
\end{abstract}

Keywords: Ispring, Learning Media, Technology

\section{PENDAHULUAN}

Pendidikan merupakan sesuatu hal yang menjadi prioritas pemerintah dalam mewujudkan pembangunan nasional, sebagaimana tertuang dalam Undang-Undang No 20 Tahun 2003 mengenai Sistem Pendidikan Nasional. Berdasarkan undang-undang tersebut, pendidikan nasional bertujuan untuk mengembangkan kemampuan dan membentuk watak serta peradaban bangsa yang bermartabat dalam rangka mencerdaskan kehidupan bangsa, berkembangnya potensi peserta didik agar menjadi manusia yang beriman dan bertakwa kepada Tuhan Yang Maha Esa, berakhlak mulia, sehat, berilmu, cakap, kreatif, mandiri, dan menjadi warga Negara yang demokratis serta bertanggung jawab (Sumargono et al., 2019).

Pendidikan merupakan salah satu sarana dalam pengembangan potensi peserta didik. Oleh karena itu, tidak dipungkiri lagi sistem pendidikan berkembang sangat pesat salah satunya dalam bidang media pembelajaran. Perkembangan Teknologi informasi dan komunikasi (TIK) di era globalisai berkembang pesat yang sejalan dengan tuntutan dan kebutuhan manusia pada berbagai bidang. Perkembangan teknologi informasi dan komunikasi telah menyebabkan terjadinya proses perubahan dalam segala aspek kehidupan, termasuk dunia pendidikan. Kehadiran media dalam proses pembelajaran 
mempunyai arti yang cukup penting, karena ketidak jelasan dan kerumitan bahan pelajaran yang disampaikan dapat dibantu dan disederhanakan dengan menghadirkan media sebagai perantara (Rahmadani et al., 2019).

Perkembangan teknologi informasi dan komunikasi memiliki pengaruh besar terhadap dunia pendidikan. Guru dapat memberikan layanan pendidikan melalui teknologi meliputi telepon, komputer, internet, maupun email. Penggunaan teknologi menyebabkan pembelajaran yang diberikan guru tidak monoton tatap muka di sekolah (Yuniasih et al., 2018). Oleh karena itu, dibutuhkan media pembelajaran yang menarik dan fleksibel seperti media berbasis digital untuk menyampaikan pembelajaran yang sulit untuk dijelaskan seperti materi yang abstrak.

Media pembelajaran digital yang digunakan pun perlu dibuat agar dapat melatih peserta didik untuk mempraktekkan keterampilan dan menerima umpan balik. Media pembelajaran interaktif dalam bentuk digital dapat dibuat dengan bantuan aplikasi yang mendukung. Salah satu aplikasi yang dapat digunakan adalah iSpring Suite 8. Aplikasi iSpring Suite 8 memiliki berbagai fitur yang dapat digunakan untuk membuat presentasi, kuis, survei, simulasi percakapan interaktif, dan lembar kerja peserta didik (LKPD). Selain itu, media yang dihasilkan dapat digunakan untuk keperluan pembelajaran daring maupun luring (Tani \& Ekawati, 2017).

Menurut Daryanto (2013) dalam (Himmah \& Martini, 2017), multimedia interaktif adalah suatu multimedia yang dilengkapi dengan alat pengontrol yang dapat dioperasikan oleh pengguna, sehingga pengguna dapat memilih apa yang dikehendaki untuk proses selanjutnya. Belajar menggunakan multimedia menyebabkan terjadinya pendekatan konstruktivis dalam proses belajar siswa dimana mereka menjadi peserta aktif dan membangun pengetahuan mereka sendiri (Himmah \& Martini, 2017). Kemajuan teknologi pembelajaran banyak menghasilkan produk yang bermanfaat bagi penunjang keberhasilan ketercapaian tujuan pembelajaran (Iriyanto, 2008) dalam (Irwanto \& Nurmalatika, 2019).

Dalam membuat konten pembelajaran berbasis teknologi informasi konten berbasis Flash merupakan salah satu aplikasi favorit yang dipakai untuk pembuatannya. Salah satu software yang dapat mengkonversi power point ke bentuk Flash adalah iSpring. Ispring adalah program yang berjalan "menumpang" pada piranti lunak yang sudah ada, dalam hal ini Ms. Power Point, yang umum dikenal dengan Add program iSpring tidak dapat berjalan sebelum program Ms. Power Point terpasang pada perangkat komputer (R. R. Martiningsih, 2014).

Cara menggunaan iSpring dalam aplikasi Power Point: Dengan mengunduh program iSpring, aplikasi ini dapat di download secara gratis dengan kisaran file $24 \mathrm{Mb}$ di http://www.ispringfree.com/download.html. Buka file presentasi yang telah dibuat di Power Point, jika animasi Anda ingin dijalankan dengan automatis (tanpa menggunakan klik atau enter) maka sebaiknya pada efek animasinya (start) tidak menggunakan on click tetapi lebih disarankan memakai efek animasi start: after previous, sehingga presentasi dapat berjalan sendiri tanda di enter atau di klik. Pastikan bahwa slide animasi yang akan diubah sudah final sesuai keinginan, dengan cara menjalankan (slide show atau tekan F5). Jika versi 2010, maka pilih iSpring (pada addres bar) lalu klik Publish, maka muncul kotak dialog Presentation title = silahkan ganti nama file yang diinginkan) Slide range $=$ klik All slides untuk di Publish Options $=$ jangan beri tanda checklist (Irwanto \& Nurmalatika, 2019).

Berdasarkan latar belakang di atas, peneliti tertarik untuk melakukan penelitian mengenai desain pembelajaran dengan menggunakan aplikasi ispring untuk menunjang pembelajaran daring. Hal tersebut dikarenakan aplikasi ispring berbasis android dapat memudahkan dalam penyampaian materi. 


\section{METODE}

Penelitian ini menggunakan metode Library Research atau Kajian Kepustakaan. Kajian pustaka merupakan suatu studi yang digunakan dalam mengumpulkan informasi dan data dengan bantuan berbagai macam referensi. Seperti jurnal maupun buku. Hasil penelitian yang dilakukan dengan medeskripsikan dari hasil desain pembuatan aplikasi iSpring.

\section{HASIL DAN PEMBAHASAN}

Salah satu produk teknologi pembelajaran yaitu Microsoft office Power Point yang telah dimasukkan menu iSpring Presenter. Ispring Presenter merupakan salah satu tool yang mengubah file presentasi menjadi bentuk Flash dan bentuk SCORM/AICC, yaitu bentuk yang biasa digunakan dalam pembelajaran dengan e-learning LMS (Learning management System). Ispring Presenter merupakan salah satu tool yang mengubah file presentasi yang kompatibel dengan Power Point untuk menjadikan bentuk Flash. Perangkat lunak iSpring tersedia dalam versi free (gratis) dan pro.

Kelebihan Ispring Suite dibandingkan software animasi iSpring terdahulu, yaitu diantaranya dengan menggunakan iSpring Suite pendidik dapat menggabungkan teks, gambar, video, animasi, simulasi, suara dan kuis dalam satu media pembelajaran. Software iSpring Suite menawarkan mode penyimpanan file power point dalam bentuk executable (exe), html5, dan flash (swf). Dengan memanfaatkan fitur tersebut, flash-like power point file dapat disimpan ke dalam file berekstensi swf (Charmonman dkk, 2015) dalam (Literasi \& Padang, 2019).

Penggunaan iSpring Suite dengan penyajian yang menarik dapat meningkatkan motivasi belajar peserta didik. Media yang komunikatif dapat menyajikan informasi materi atau konsep yang ada pada media sebagai sumber pesan kepada peserta didik sehingga mampu meningkatkan hasil belajar peserta didik ( Himmah \& Martini, 2017) dalam (Pada et al., n.d.).

ISpring Suite 6.2 merupakan software yang dapat mengubah file presentasi menjadi bentuk Flash dan secara mudah dapat diintegrasikan dalam Microsoft Power Point sehingga penggunaannya tidak membutuhkan keahlian yang rumit. Ispring Suite menyatukan produk profesional untuk menciptakan program kelebihan lain yang dimiliki program ispring Suite 6.2 adalah mampu membuat soal-soal uji kompetensi yang memiliki kelebihan jika digunakan akan selalu mengacak nomor-nomor soal dan option jawaban yang ada antara user yang satu dengan user yang lainnya seperti soal-soal yang diterapkan dalam Ujian Nasional ataupun Tes CPNS saat ini. E-learning yang efektif, serta kuis dan interaksi yang akrab di lingkungan Power Point. Selain itu dengan iSpring Suite 6.2, file dapat dikonversi dan dipublikasikan (publish) ke dalam file aplikasi (exe) maupun dipublikasikan ke jaringan internet melalui blog yang dimiliki oleh guru pengampu (Surakarta et al., 2019).

Ispring Suite 7 merupakan salah satu tool yang terintegrasi dengan Micsrosoft Power Point. Setelah selesai dibuat, media dterbitkan dalam bentuk HTML dan selanjutnya agar bisa dijalankan pada perangkat android digunakan perangkan lunak Intel XDK. Selain itu juga digunakan perangkat lunak Benetton GIF serta Corel Draw. Adapun perangkat keras yang digunakan adalah laptop, kabel data, dan telepon pintar android minimal versi 5.0 (Sasahan et al., 2017).

Salah satu software yang dapat mengonversi Power Point ke bentuk Flash adalah iSpring Suite 8 . Software iSpring Suite 8 adalah program yang berjalan "menumpang" pada piranti lunak yang sudah ada, dalam hal ini Ms. Power Point, yang secara umum dikenal sebagai Add program. Artinya, iSpring Suite 8 tidak dapat berjalan sebelum program Ms. Power Point terpasang pada perangkat komputer. Selain harus terpasang Ms. Power Point, komputer juga harus sudah terpasang flash player. Hal ini diharuskan 
karena iSpring Suite 8 menyediakan fasilitas untuk mengubah dokumen Ms. Power Point menjadi file flash, menyisipkan file flash ke dalam Ms. Power Point. Untuk mendukung fasilitas tersebut, iSpring Suite 8 memerlukan plug player (Martiningsih, 2018).

Pada penelitian ini peneliti menggunakan iSpring suite 9, dimana dalam iSpring Suite 9 dapat membuat beragam tipe konten e-learning seperti memasukkan kuis, simulasi dialog, interaksi maupun perekam layar langsung ke presentasi Power Point.

Microsoft Powerpoint adalah software yang telah menyediakan fasilitas untuk membantu dalam penyusunan sebuah presentasi yang efektif, profesional, dan juga mudah. Microsoft Power Point membantu menyampaikan suatu gagasan menjadi lebih menarik dan jelas tujuannya (Afandi, 2009).Desain pembelajaran dengan menggunakan iSpring ini mengintegrasikan dengan Microsoft Power Point. Berikut tampilan desain pembelajaran ispring .

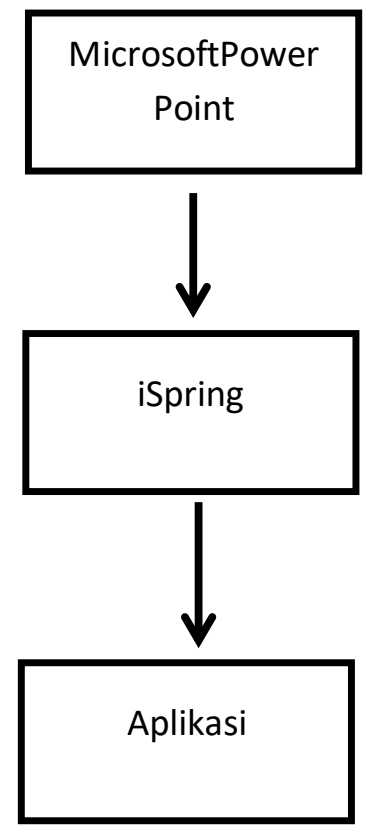

Bagan 1. Alur pembuatan ispring

Penjelasan dari desain di atas bahwasannya dalam pembuatan media pembelajaran berbasis e-learning menggunakan iSpring untuk proses pembelajaran. Berikut ini contoh tampilan media pembelajaran berbasing e-learning menggunakan iSpring:

Yang dilakukan pertama kali, harus mendesain media pesentasi di Microsoft Power Point terlebih dahulu. Pada saat ingin membuat animasi lebih baiknya menggunakan efek animasinya (start) tidak menggunakan on click tetapi lebih disarankan memakai efek animasi start : after previous, sehingga presentasi dapat berjalan sendiri tanda di enter atau di klik.

\section{Gambar 1. Tampilan ppt setelah menginstal iSpring.}

Pada tampilan Power Point setelah menyelesaikan slide pekerjaan langsung klik iSpring Suite, setalah itu klik publish. Sehingga akan muncul tampilan seperti gambar dibawah ini. 


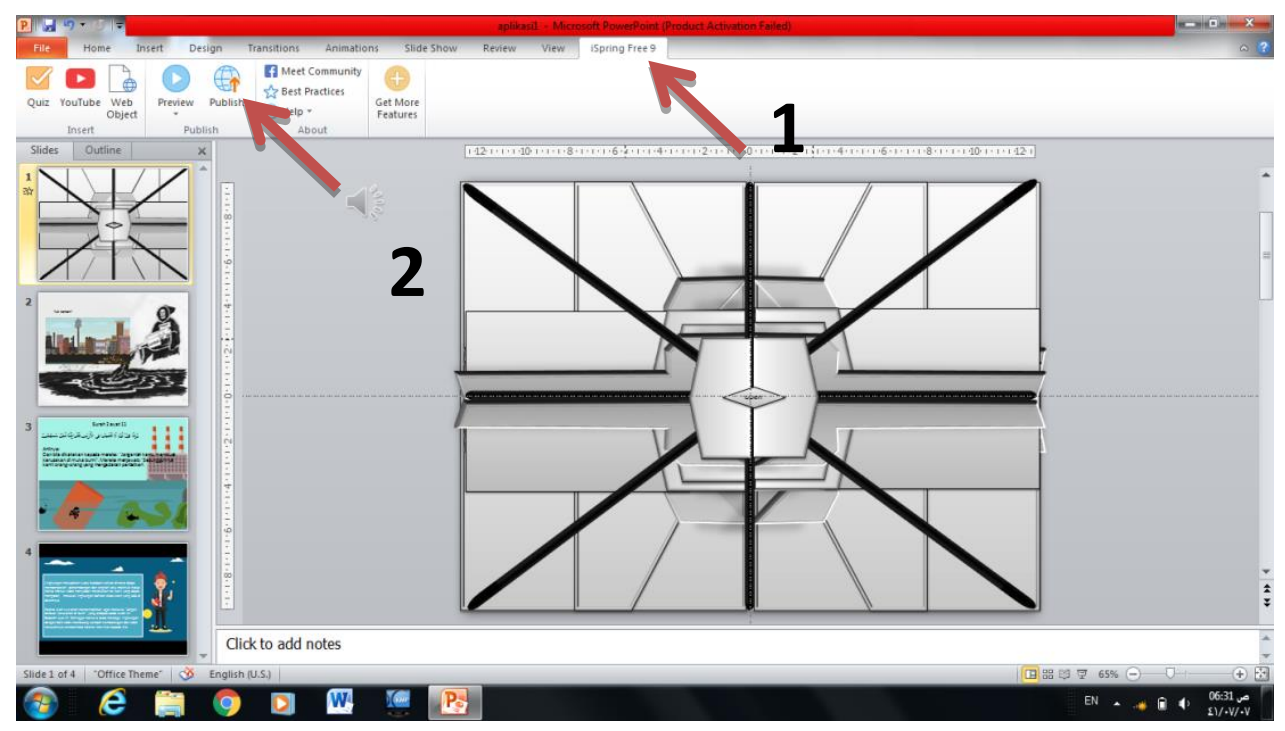

Gambar 1. Tampilan ppt setelah menginstal iSpring

Pada tampilan Power Point setelah menyelesaikan slide pekerjaan langsung klik iSpring Suite, setalah itu klik publish. Sehingga akan muncul tampilan seperti gambar dibawah ini.

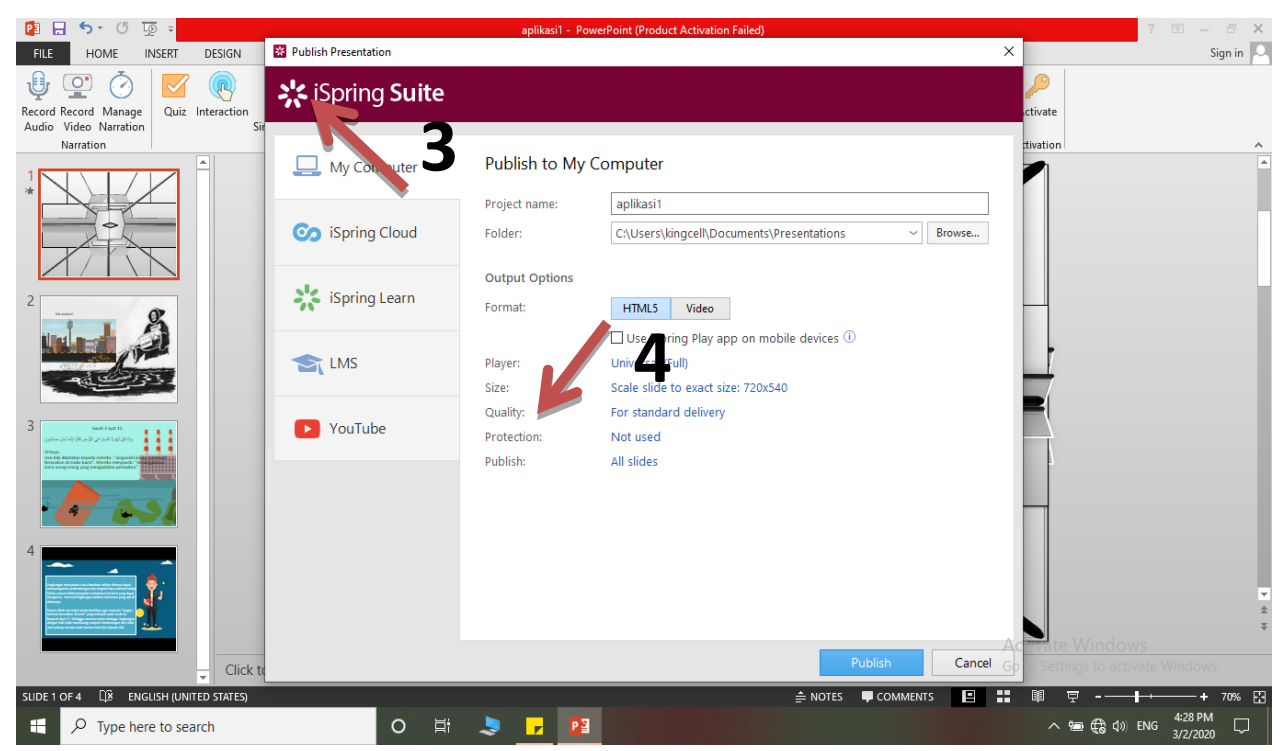

Gambar 2. Tampilan iSpring suite saat akan melakukan proses publish menjadi html

Tampilan iSpring sebelum proses mempublish Power Point menjadi animasi harus melakukan tahap ini sehingga saat proses mempublish akan terus berlanjut ketahap selanjutnya, seperti pada gambar dibawah ini. 


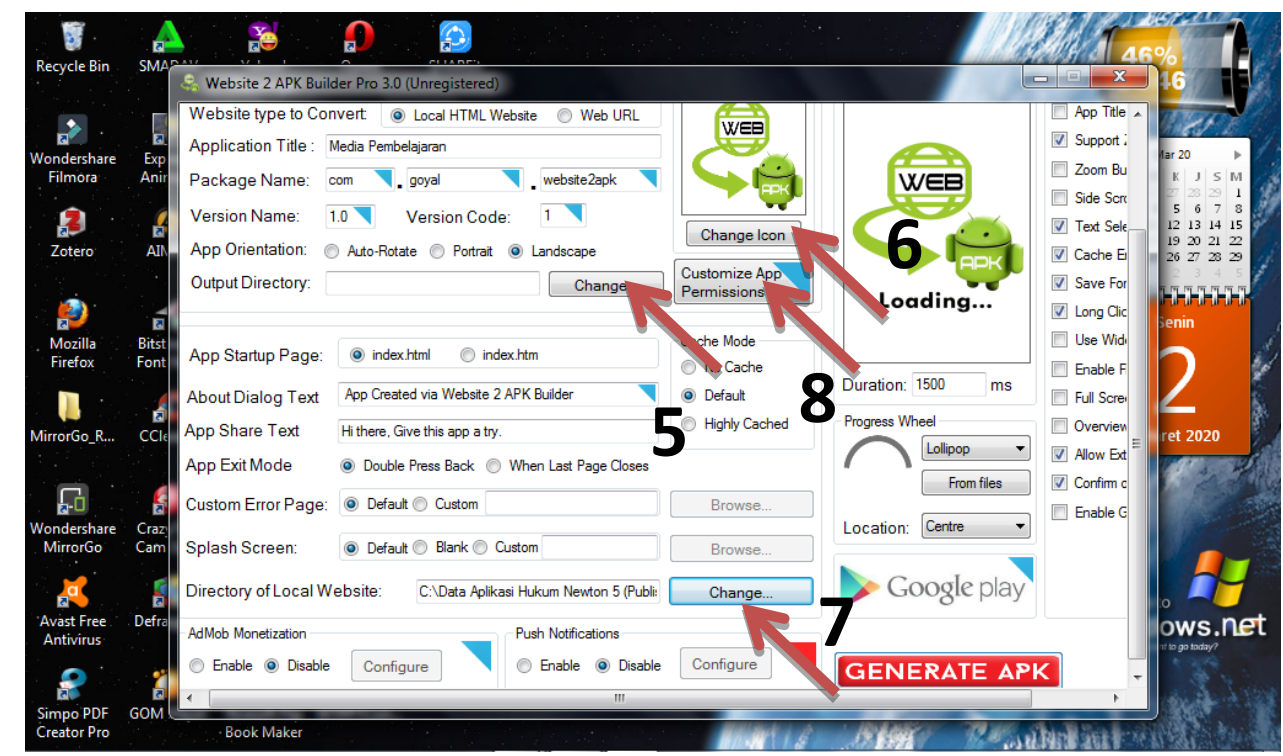

Gambar 3. Tampilan proses akhir tampilan ISpring menjadi aplikasi

Pada proses akhir, yang pertama yang harus dilakukan output directory yang akan dijadikan aplikasi, yang kedua yaitu change Icon sesuai isi dari aplikasi, setelah itu menentukan aplikasi akan disimpan dimana klik directory of local website, dan yang terakhir custumize app permissions.

Pembelajaran e-learning mengguakan iSpring membantu peserta didik dalam memanfaatkan teknologi dengan cerdas. Materi yang telah dibuat menggunakan file presentasi Microsoft Power Point telah menjadi aplikasi sehinngga siswa dapat mengakses pembelajaran tersebut. Aplikasi yang telah dibuat dapat di simpan melalui handpone pesertadidik. Aplikasi materi ini juga dapat di akses pada Play Store saat aplikasi tersebut di daftarkan di dalam play store dengan memenuhi persyaratan yang telah ditentukan oleh play store. Setiap orang perlu update informasi dan IPTEK guna mengimbangi perubahan sosial dan perkembangan teknologi. Pada tahapan pertama yang dilakukan oleh peserta didik yaitu mengakses aplikasi melalui link yang telah dibagikan oleh pendidik, sehingga peserta didik dapat mengakses secara otomatis dan muncul di layar beranda.

Pada media iSpring tidak hanya digunakan sebagai media presentasi Flash sebagai proses pembelajaran tetapi juga dapat digunakan sebagai pembuatan kuis dalam proses pembelajaran. Oleh karena itu, iSpring membantu dalam proses pembelajaran berbasis e-learning.

Proses pembelajaran menggunakan iSpring ini akan membantu peserta didik belajar sesuai dengan gaya belajar setiap peserta didik. Kebebasan saat belajar akan diperoleh peserta didik tampa keterbatasan waktu dan Iokasi.

\section{KESIMPULAN}

Pemanfaatan Microsoft Power Point terintegrasi iSpring dapat dijadikan alternatif desain dalam pembuatan media pembelajaran ICT. Isprig Suite 9 dapat membuat beragam tipe konten e-learning serperti memasukkan kuis, simulasi dialog, interaksi maupun perekam layar langsung ke presentasi Power Point. Media yang dihasilkan terintegrasi secara baik melalui tampilan audio visual yang menjadikan proses belajar 
mengajar lebih menarik, sehingga dapat memotivasi dan materi yang disampaikan dalam desain aplikasi iSpring Suite 9 lebih dapat dipahami.

\section{DAFTAR PUSTAKA}

Afandi, A. (2009). Media Ict Dalam Pembelajaran Matematika Menggunakan Powerpoint Interaktif. 19-26.

Gerak, K., Belajar, M., \& Tarongong, S. (2019). Edu Komputika Journal. 6(2), 38-48.

Kelas, M., Sdn, V. Di, Kota, C., Yuniasih, N., Aini, R. N., \& Widowati, R. (2018). Pengembangan Media Interaktif Berbasis Ispring Materi Sistem Pencernaan. 8(2), 85-94.

Keperawatan, K., \& Nutrisi, D. (2009). Penggunaan media pembelajaran i-spring presenter untuk meningkatkan motivasi belajar dan hasil belajar pada mata kuliah keperawatan dasar nutrisi 11. 363-369.

Literasi, M., \& Padang, S. (2019). Natural Science: Jurnal Penelitian Bidang IPA dan Pendidikan IPA ( Print ISSN 2477 - 6181) Penerapan Model Trait Treatment Interaction Berbantuan Aplikasi Ispring. 861-875.

Martiningsih, R. (2018). Menggunakan Aplikasi Ispring Suite 8 The Increase of Set Learning Outcomes By Using iSpring Suite 8 Aplication. 1-13.

Materi, J., Jmpf, F., Tani, S., \& Ekawati, E. Y. (2017). Peningkatan Kemandirian Belajar Peserta Didik pada Materi Teori Kinetik Gas Melalui Penerapan Media Pembelajaran Interaktif Berbasis iSpring Suite 8. 7, 13-16.

Multimedia, P., Menggunakan, I., Suite, S., Studi, M. P., Sains, P., Unesa, F., Jurusan, D., Fmipa, I. P. A., Penelitian, A., Suite, S., Smpn, V., Mojokerto, P., Pretest, O. G., Design, P., Suite, S., Suite, S., Suite, S., Suite, S., Kunci, K., \& Suite, S. (2017). PENGEMBANGAN MULTIMEDIA Interaktif Menggunakan Ispring Suite 8 Pada Sub Materi Zat Aditif Untuk Meningkatkan Hasil Belajar Siswa Smp Kelas Viii. 2, 73-82.

No Title. (2016).

Pada, S., Sistem, K., Di, E., \& Menengah, S. (n.d.). No Title. 13.

pada siklus pertama dan aplikasi. (2015). 134-145.

Palopo, U. C. (n.d.). Pengembangan Media Pembelajaran Matematika Menggunakan Powerpoint Dan. 2(3), 53-61.

Sasahan, E. Y., Oktova, R., \& N, O. O. I. R. (2017). Pengembangan Media Pembelajaran Interaktif tentang Optika Berbasis Android Menggunakan Perangkat Lunak Ispring Suite 7 . 0 untuk Mahasiswa S - 1 Pendidikan Fisika pada Pokok Bahasan Interferensi Cahaya. 52-61.

Surakarta, S., Susanto, H., \& Rachmedita, V. (2019). Pengembangan Media Pembelajaran Sejarah Berbantuan Ispring Suite 6.2 Untuk Meningkatkan Hasil Belajar Pada Siswa Kelas Xi Ips. 2(1), 82-99. 